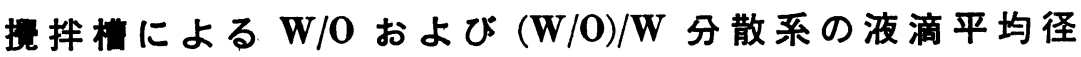

\author{
高 橋 勝 六・大 坪藤 夫 \\ 竹内寛 \\ 名古屋大学工学部 化学工学科*
}

\begin{abstract}
萝拌槽を肞いて乳化剂として Span 80 を添加したケロシン中に分散した水滴（W/O エマルジョ ン) および水中に分散した $\mathrm{W} / \mathrm{O}$ エマルジョン滴（(W/O)/W エマルジョン）の滴径を測定した.

$\mathrm{W} / \mathrm{O}$ 系での滴径分布は対数正規分布で表される.W/O および (W/O)/W 系での体面積平均径は

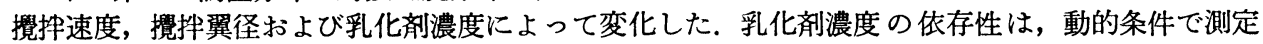
した界面張力の変化と一致した。乳化剂を添加した W/O 系では滴の合一が起こりにくいので, 滴 径は分散相分率によって変化せず，ウェーバー数に対する平均径の依存性も乳化剤無添加系に対す る文献值より大きくなった。
\end{abstract}

\section{緒}

$(\mathrm{W} / \mathrm{O}) / \mathrm{W}$ エマルジョンは水中に分散した油滴中に水 滴が分散している3 相エマルジョンである. 最近, 液体 膜を用いた分離操作が省エネルギー的分離法あるいは水 処理などでの希薄溶質の分離法として注目されてい $ろ^{5,6)}$. この操作は 3 相間の物質移動を含み, 有効な分離 の達成には液膜を薄くでき，大きな界面積が得られる 3 相エマルショョが有利と考えられ，3相エマルショョン系

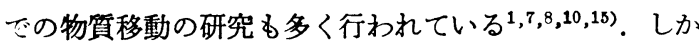
し, 界面積および液膜厚さの算出の基となる分散滴およ び内部分散滴の滴径については不明の点が多い.

翼䢁槽による液一液分散系の滴径は，乳化剤が添加さ れていない系については多く研究されているが，乳化剤 を添加した場合についての測定は少なく ${ }^{12,13)} ， 3$ 相エマ ルジョン系についての報告は見当たらない，本研究では 櫬汼槽を用いて乳化剂を添加した油相中に分散した水滴 (W/O系) および水相中に分散した W/O エマルジョン 滴 ((W/O)/W 系) の滴径分布ならびに平均滴径を測定 し, 滴径に及ぼす乳化剤濃度, 擤拌速度, 分散相分率な どの影響について検討した。

\section{1. 実験}

油相にはケロシン $\left(157 \sim 246^{\circ} \mathrm{C}\right.$ の留分) を, 水相に は蒸留水を使用し, 安定な分散を得るために油相に乳化 剤として親油性界面活性剤 Span 80 (ソルビタンモノオ レエート，HLB=4.3）を添加した.

エマルシション作製に使用した攪拌槽の 概略を Fig. 1 に示す. 槽は内径 $10 \mathrm{~cm}$ のア.クリル製で幅 $1 \mathrm{~cm}$ の邪 魔板 4 枚をるち， $25 \pm 0.5^{\circ} \mathrm{C}$ の恒温水用ジャケットを備

* 广464 名古屋市千種区不老町
えた，靦挥翼には翼径 $3.3 \mathrm{~cm}$ の 6 枚平羽根タービン型 を用いた，W/O 系では，槽中で所定量の油相を筧拌し ながら所定量の水相を注入して分散させた（W/O)/W 系では, 水相を䨘拌しながら W/O エマルジョン相 $(N$ $=1,200 \mathrm{rpm}$ で 1 時間擤拌して作製）を液表面の中央付 近に先端をカットしたピペットにより注入して分散させ た。この際, 液表面近傍にェマルジョン相が層状に分離 することを防ぐため, 槽底から $2.5 \mathrm{~cm}$ と $7.5 \mathrm{~cm}$ の位 置に2 個の靦拌翼を設けた。 また翼径 $5.0,6.7 \mathrm{~cm}$ の描 拌翼での実験も行った。

分散滴径は顕微鏡写真により測定した。撮影に際して W/O 系の場合, 顕微鏡用ガラス皿に油相を入れ；その 中へ少量の試料を採取し, 水滴の分散密度を小さくして 滴の重なりを防いだ。 また (W/O)/W 系の場合，W/O エマルジョン滴を水面上に浮かせて速やかに撮影した.

Fig. 2 に (W/O)/W 系で内部分散滴の構造を明膫にし た写真を示す。

\section{2. 実験結果および考察}

\section{$2 \cdot 1$ 滴径分布}

熼汼開始 1 時間後における W/O および $(\mathrm{W} / \mathrm{O} / \mathrm{O}) / \mathrm{W}:$ 系 の分散滴径の分布を Fig. 3 に示す. 図中の実線は油相 中の水滴の分布が対数正規分布に近い分布を示し，また 靦拌速度の增加につれて滴径が小さくなることが認めら れる.これらの分布の幾何標準偏差は $2.0 \sim 2.3$ の範囲 にあり, 䚓拌速度によってあまり変化しない. 乳化剂添 加系の分散滴径分布として築山ら ${ }^{12,13)}$ は正規分布を報告 しておうり，Fig. 3 の結果とは異なる. 本実験でも乳化㶡 濃度が低く攪拌速度が小さい場合は滴径は大きく，その 分布は正規分布に近づいた，乳化剤無添加系について山 口ら ${ }^{17)}$ は, 界面張力が大きい場合は正規分布を示し, 界 


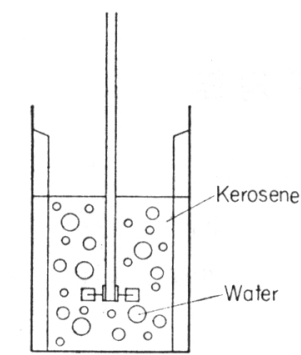

Two-phase emulsion (W/O)

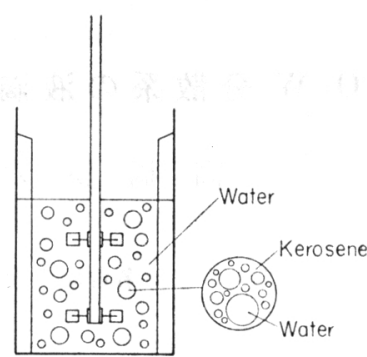

Three-phose emulsion $((W / O) / W)$
Fig. 1 Schematic diagram of agitated vessel

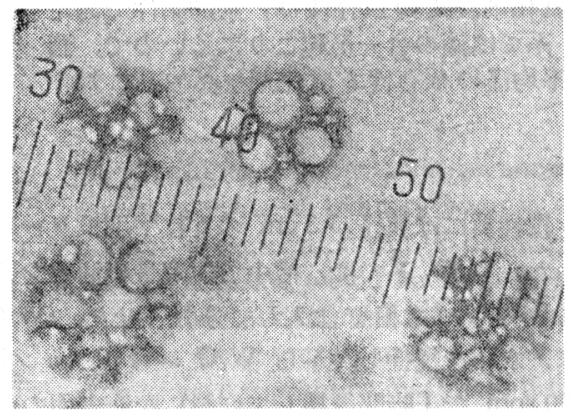

Fig. 2 Photograph of $(\mathrm{W} / \mathrm{O}) / \mathrm{W}$-dispersion

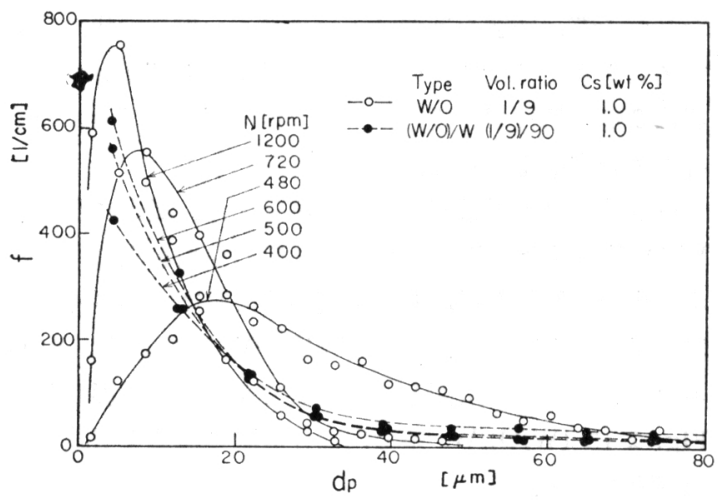

Fig. 3 Drop size distributions of water drops in oil and W/O-emulsion drops in water

面張力が小さくなると対数正規分布に近づくと，指摘し ている。また Spraw ${ }^{11)}$ は界面張力の小さい系で対数正 規分布に近い分布を報告している，乳化剤添加系では一 般に乳化剂濃度が高くなると界面張力は減少する。した がって, 本実験の滴径分布は山口らの指摘と一致してい る.

(W/O)/W 系に拈ける W/O エマルジョン滴の滴径分 布をFig. 3 に破線で示す。醔拌速度が小さい場合でも $20 \mu \mathrm{m}$ 以下の滴は多いが，大きな滴の分率も大きく W/O 系の分布特性と異なる. Fig. 4 は同じデータに対 する体積分布を示す．䚓拌速度による分布の差が明瞭に 現れており，100 $\mu \mathrm{m}$ を越える大きな滴も存在する。な

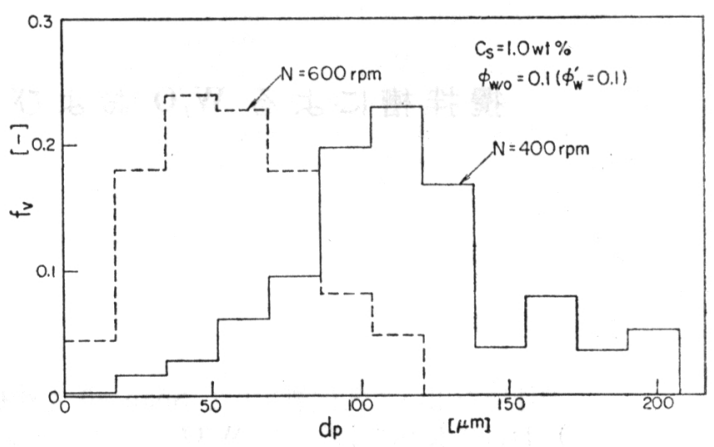

Fig. 4 Volume fraction distributions of W/O-emulsion drops in water

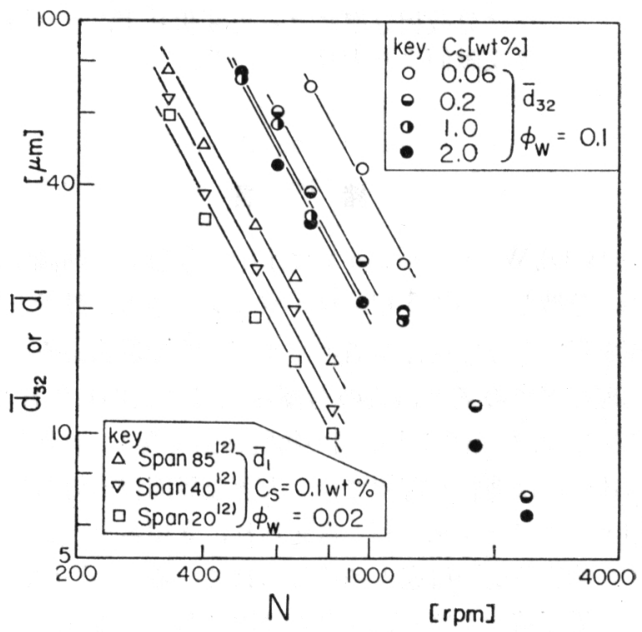

Fig. 5 Effect of impeller speed on mean drop diameter for water drops in oil

括，滴内分散水滴径を直接測定することはできないが，

Fig. 3 に示した W/O 系の $N=1,200 \mathrm{rpm}$ での滴径分布 をもつ滴が存在すると推察される。

\section{$2 \cdot 2 \mathrm{~W} / \mathrm{O}$ 系の平均滴径}

接触界面積を算出するための滴径としては

$$
d_{32}=\sum\left(n d_{p}{ }^{3}\right) / \sum\left(n d_{p}{ }^{2}\right)
$$

で表される体面積平均径の使用が便利である，種々の乳 化剤濃度に打ける分散水相分率 $\phi_{W}=0.1$, 攪拌 1 時間後 の $d_{32}$ を靦拌速度 $N$ に対して Fig. 5 にブロットした。 $N<1,000 \mathrm{rpm}(R e<20,000)$ での実線は傾き -1.9 の直 線である.この依存性は, 乳化剂無添加系に対する -1.2 乗 ( $W e$ 数に対して -0.6 乗 $)^{2,3,4, \theta, 14)}$ に比べて大きい. 乳化剤添加系ではエマルジョンを数日静置しても滴径に 変化はみられず，滴の合一がない完全分散支配であるこ とが特徵である. 乳化剤無添加系でもSpraw ${ }^{11)}$ は筧拌 翼近傍の分散支配位置ではー3/2 乘の大きな依存性を報 告している.な拉 $N>1,500 \mathrm{rpm}$ では描拌を停止した とき気泡の上昇が観察されたことから液表面から吸い込 


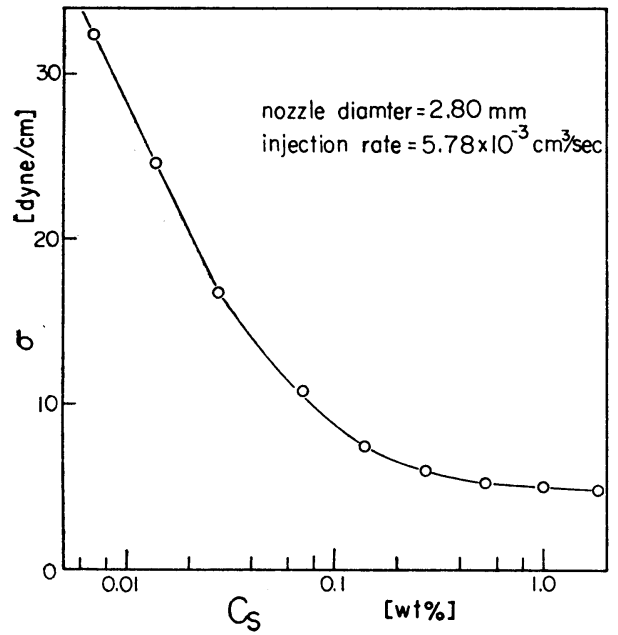

Fig. 6 Interfacial tension between water and kerosene containing Span-80. The values of $\sigma$ were determined from the volume of water drop injected from nozzle into oil phase

まれる気泡が影響していると考えられる．Fig. 5 には Span 系の 3 種の乳化剂を使った筑山ら ${ }^{12}$ のデータも示 したが，長さ平均径 $d_{1}$ の $N$ に対する依存性は図示し た值線で示すよ5に本実験とほぼ一致する． $d_{1}$ と $d_{32}$ の 相異は滴径分布にもよるが，本実験結果によれば $d_{32} / d_{1}$ $\fallingdotseq 1.5$ であった. 油相中の乳化剂濃度 $C$ s が小さくなる と $d_{32}$ は大きくなるが，これは界面張力 $\sigma$ の增加に起 因すると考えられる。

Fig. 6 にC、による $\sigma$ の変化を示す.この $\sigma$ はノズ ルから一定体積速度で水相を油相中に滴下し, その滴体 積を測定して得られた值で，動的な測定法によるため静 的界面張力とは異なる. Fig. 5 に示した $d_{32}$ の $C_{s}$ によ る変化は Fig. 6 の $\sigma$ の変化に対応しており, 液滴の分 裂に影響する界面張力は動的な值が重要となることを示 唆する.

分散相分率 $\phi_{W}$ と $d_{32}$ の関係を Fig. 7 に示す. $C_{8}$ が 大きい場合は $d_{32}$ に影著な変化は認められないが， $C_{8}=$ $0.2 \mathrm{wt} \%$ では $\phi_{W}=0.1$ に比べて $\phi_{W}=0.5$ での $d_{32}$ は 2 倍以上大きくなる.そこで後者のエマルジョンを数日 静置した後, 上澄みの油相液を採取して水との界面張力 を測定した. Fig. 8 はその結果を $\phi_{W}$ に対してブロッ トしたるのである． $\phi_{W}$ の增加につれて $\sigma$ が大きくなる のは， $C_{8}$ が一定のため油相中の乳化剂が界面に吸着さ れて希薄になり，界面への乳化剂の供給が減少すること 飞起因する．この事実からC，が小さい場合， $\phi_{W}$ が增 加するにつれて滴径が大きくなったと推定される. しか

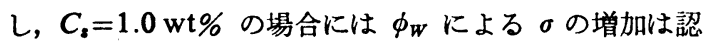
められず, 油相中の乳化剂濃度が大きく变化するのは C.が $0.2 \mathrm{wt} \%$ 以下の場合に限られる現象である.これ

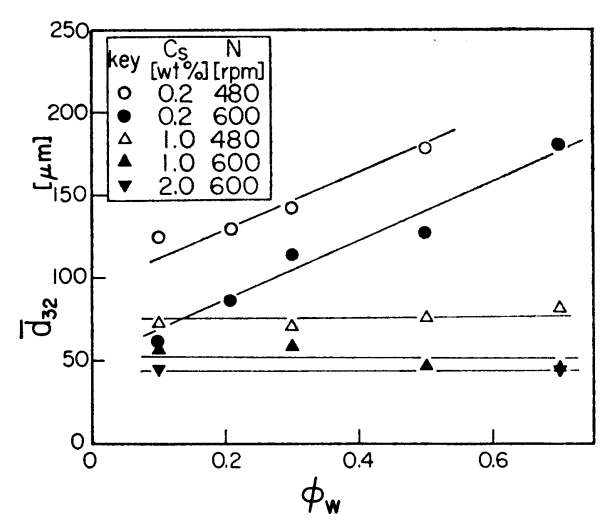

Fig. 7 Effect of dispersed phase fraction on Sauter mean diameter of water drops in oil

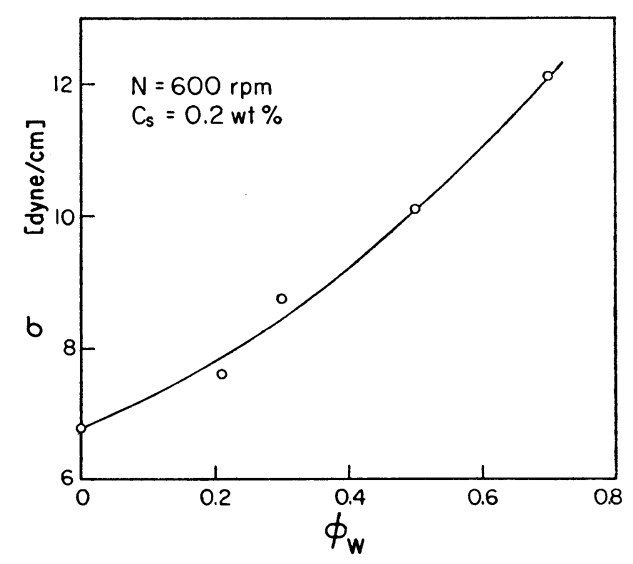

Fig. 8 Interfacial tension between water and oil phase separated from W/O-emulsion

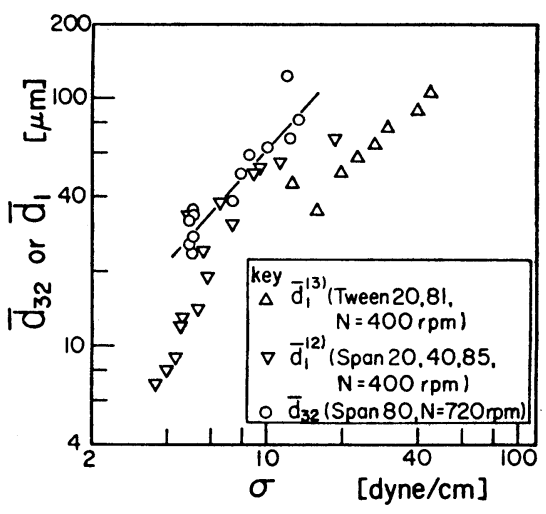

Fig. 9 Effect of interfacial tension on mean drop diameter

らの事実から， $C_{s}>1.0 \mathrm{wt} \%$ の乳化剂添加系では分散 相分率によって滴径は大きく変化しないと考えられる.

上述したように滴径は界面張力に依存するので Fig. 9 


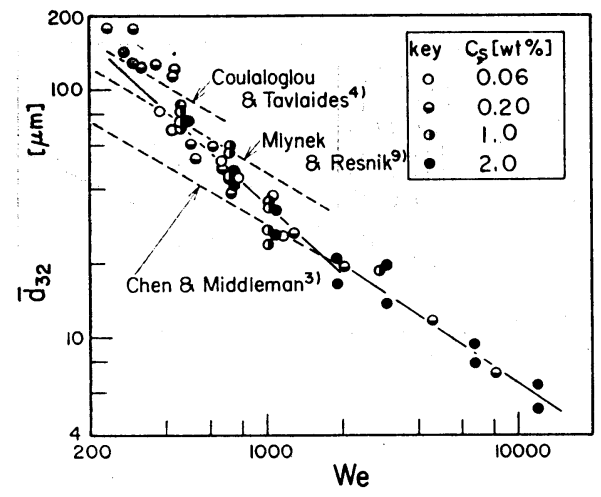

Fig. 10 Correlation of Sauter mean diameter of water drops in oil

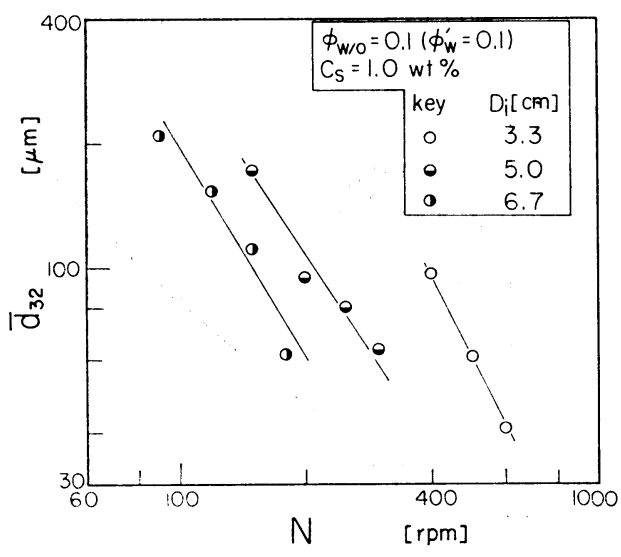

Fig. 11 Effect of impeller speed on Sauter mean diameter of W/O-emulsion drops in water

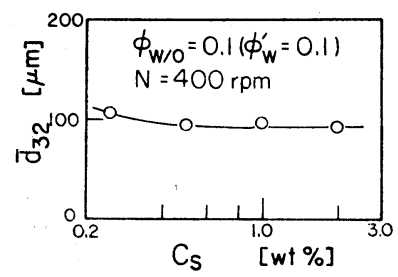

Fig. 12 Effect of concentration of emulsifying agent on Sauter mean diameter of W/O-emulsion drops in water

に $d_{32}$ を $\sigma$ に対してプロットした. 四中の実線は傾き 1.0 の直線であり， $d_{32}$ は $\sigma$ K比例して增大する. 戝に は筑山ら ${ }^{12,13)} の d_{1}$ に対するデータも併せて示した。 Tween 系乳化剈では比例関係が得られるが，Span 系 ではのの大きい領域すなわち, 乳化剤濃度が低いとき $d_{1}$ が急激に增加している. Fig. 10 は $d_{32}$ を $W e$ 数に 対してプロットしたもので, $W e<2,000$ での実線は $\phi_{W}$ $=0.1$ のデータについて最小 2 乗法で決定した次式を表 している.

$$
d_{32}=2.4 \times 10^{4} W e^{-0.85}
$$

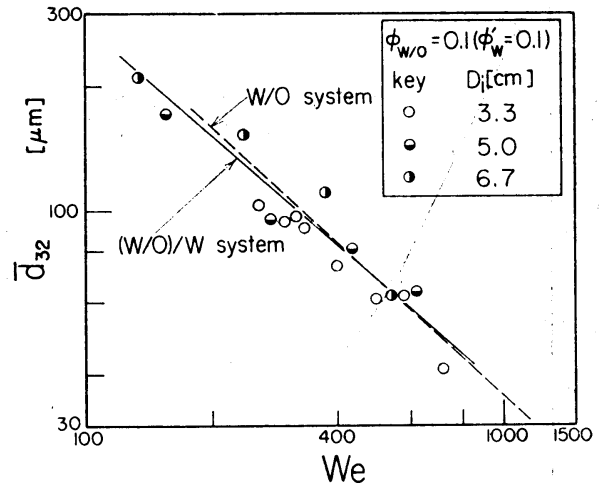

Fig. 13 Correlation of Sauter mean diameter of W/Oemulsion drops in water

ここで $d_{32}$ は $\mu \mathrm{m}$ で表したものである.しかし， $\phi_{W} か ゙$ 大きく $C_{\mathbf{3}}=0.2 \mathrm{wt} \%$ の場合はこの実線より上方に偏倚 してくる. Fig. 10 には乳化剂無添加系に対して報告さ れている実験式を破線で示したが，本実験結果はこれら に比べて傾きが大きい.一方, $W e>2,000$ では $W e$ 数 の依存性は一 0.7 乗と小さくなるが，櫬拌速度が大きい ため気泡吸い込及の寄与と考兄られる。

\section{$2 \cdot 3(\mathrm{~W} / \mathrm{O}) / \mathrm{W}$ 系の平均滴径}

W/O 系の分散水滴は上述したようにほとんど合一し ないのに反して，水中に分散した W/O ェマルジョン滴 は合一し易く，静置すると W/O エマルジョン相と水層 に分離する. Fig. 11 は分散エマルジョン相分率 $\phi_{W / O}$ $=0.1$, 内部分散水相分率 $\phi_{W}{ }^{\prime}=0.1, C_{s}=1.0 \mathrm{wt} \%$ K拈 ける $d_{32}$ の $N$ に対するプロットを示す. $N$ への依存性 は Fig. 5 に示した W/O 系の場合と同様, 乳化剤無添 加系に比べると大きい. $N$ が小さいと W/O エマルジ ヨン層が形成され易く均一分散しなくなるが，摫拌翼径 $D_{i}$ が大きくなると均一な分散領域は $N$ の小さい方へ 移行する.

乳化剤濃度に対する $d_{32}$ の变化を Fig.' 12 に示す。 $C_{8}>0.5 \mathrm{wt} \%$ では滴径の変化は認められない。一方, 乳 化剂濃度が低くなると W/O 系の場合と同様に界面張力 の增加のため $d_{32}$ は大きくなる傾向を示し, $N=500$ $\mathrm{rpm}, C_{s}=0.25 \mathrm{wt} \%$ の場合にも $d_{32}$ は $C_{s}=1.0 \mathrm{wt} \%$ で の $d_{32}$ より $20 \%$ 大きくなった. $d_{32}$ を $W e$ 数に対し てプロットすると Fig. 13 に示すように $D_{i}$ の影響は 小さくなり

$$
d_{32}=1.7 \times 10^{4} W e^{-0.89}
$$

で相関される．ここで $d_{82}$ は $\mu \mathrm{m}$ で表したものである. 乳化剂無添加系では $d_{32} / D_{i}$ が $W e$ 数により相関されて いるが ${ }^{8,4)}$, 本実験結果は $d_{32} / D_{i} よ り d_{32}$ を用いた方が よい相関を与える. 比較のため Fig. 13 に/O 釆に 対する Eq. (2) を破線で示した，同じ翼径について比較 
すると W/O 系 $\left(D_{i}=3.3 \mathrm{~cm}\right)$ の $d_{32}$ が少し大きいが， (W/O)/W 系では䚓拌翼を2 枚借えていることをる考虑 すると，両者に本質的な差はないと考えられる. (W/O)/ $\mathrm{W}$ 系の $d_{32}$ の $W e$ 数に対する依存性は $\mathrm{W} / \mathrm{O}$ 系の場 合と乳化剂無添加系の間にある.

内部分散水相分率と $d_{32}$ の関係を Fig. 14 に示す. $d_{32}$ は $\phi_{W^{\prime}}$ によって汪とんど变化しないが， $\phi_{W^{\prime}}$ が大 きくなるにつれてわずかに大きくなる，それは测定誤差 程度であるが $\phi_{W^{\prime}}{ }^{\prime}$ の增加に伴う W/O エマルジョンの 粘度の增大に起因するとも考えられる.このことは, 乳 化剂無添加系では分散相の粘度が大きくなると $d_{32}$ はわ

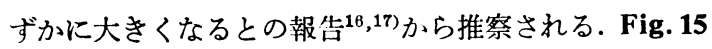
は分散W/O エマルジョン相分率の $d_{32}$ に及ぼす影響を 示す. $\phi_{W / O}$ が 0.2 以上の領域で $d_{32}$ は減少する傾向を 示す.一方, 滴の合一が起こり易い乳化剂無添加系では分 散相分率の増加とともに $d_{82}$ は大きくなるが2,4,9,14,18,17)， 滴の合一が起こりにくい乳化剂を添加した W/O 系で はFig. 7 に示したようにC。を大きくすれば $d_{32}$ は $\phi$ に 依存しなくなる。(W/O)/W 系の分散滴の合一寸る傾向 は雨者の中間と考えられ，合一の難易によって $d_{32}$ の減 少を説明することはできない，したがって $(\mathrm{W} / \mathrm{O}) / \mathrm{W}$ 系 では分散相分率は滴の分裂過程を支配する因子と考えら れるが，その影響は明らかでない. しかしながらェマル ジョン相を連続水相から分離すると, $\phi_{W / O}$ が最初の值 より大きくなる実験事実を考慮し，乳化液体膜による分 離操作では $\phi_{W / O}>0.2$ の範囲は好ましい条件とは言兄 ないことから， $\phi_{W / O}$ による $d_{32}$ の減少は工業的にはあ まり問題にならない。

\section{結 喜}

摫拌槽で油相に乳化肪を添加して液一液分散を行い, 分 散滴径分布を測定し次の結果を得た。

1) W/O 2 相系の滴径は対数正規分布に従い，(W/ O)/W 3 相系では 2 相系と異なり微小滴から大きな滴ま で広く分布する。

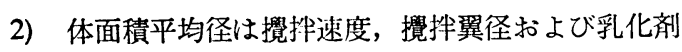
濃度によって大きく变化する．乳化剂濃度による界面張 力の変化は, 滴径に対しては動的界面張力が影篦因子と なる、

3）W/O 系および (W/O)/W 系の体面積平均径は, Eq. (1) および Eq. (2) で相関されるが，We 数への依存 性恃両者々も乳化剈無添加系に比べて大きい.この原因 は乳化剤添加系では滴が合一しにくいことによる。

4) W/O 系では水相分率によって滴径は変化しない が，乳化剤濃度が低い場合，水相分率を大きくすると油 相中の乳化剂濃度が減少し，その結果滴径は大きくな る.

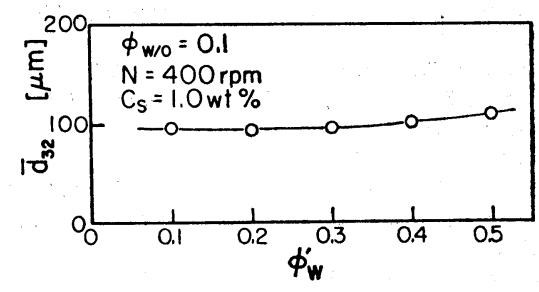

Fig. 14 Effect of volume fraction of water phase dispersed in oil drop on Sauter mean diameter of W/O-emulsion drops in water

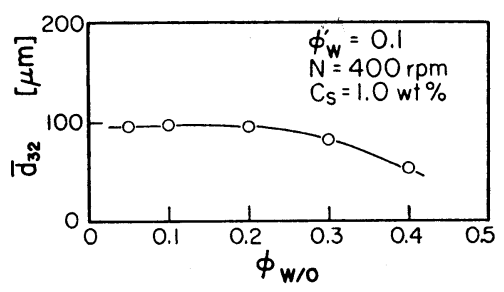

Fig. 15 Effect of dispersed phase volume fraction on Sauter mean diameter of W/O-emulsion drops in water

\section{Nomenclature}

$C_{s}=$ concentration of emulsifying agent in oil phase

$D_{i} \quad=$ impeller diameter

[wt\%]

$d_{p}=$ drop diameter

$d_{1}=$ mean diameter of drops

$d_{32}=$ Sauter mean diameter of drops

$f \quad=$ probability density of drop diameter in term of number, $\Delta n /\left(\Delta d_{p} \cdot n_{t}\right) \quad[1 / \mathrm{cm}]$

$f_{v} \quad=$ relative frequency referring to volume of drops, $\Delta V / V$

$N=$ impeller speed

$n=$ number of drops counted

$n_{t}=$ total number of drops counted

$V=$ volume of drops counted

$W e=$ Weber number, $D_{i}{ }^{3} N^{2} \rho / \sigma$ [cm] $[\mu \mathrm{m}]$ $[\mu \mathrm{m}]$ $[\mu \mathrm{m}]$

$\rho \quad=$ density of continuous phase $\quad\left[\mathrm{g} / \mathrm{cm}^{3}\right]$

$\sigma \quad=$ interfacial tension between liquid phases

$\phi_{W}=$ volume fraction of water phase

dispersed in oil [-]

[dyne $/ \mathrm{cm}$ ]

$\phi_{W^{\prime}}=$ volume fraction of inner water phase dispersed in oil drop

$\phi_{W / O}=$ volume fraction of $\mathrm{W} / \mathrm{O}$ emulsion phase dispersed in water

\section{Literature cited}

1) Cahn, R. P. and N. N. Li: Sep. Sci., 9, 505 (1976)

2) Calderbank, P. H.: Trans. Instn. Chem. Engrs., 36, 443 (1958)

3) Chen, H. T. and S. Middleman: AIChE J., 13, 989 (1967)

4) Coulaloglou, C. A. and L. L. Tavlarides: AIChE J., 22, 289 (1976) 
5) Halwachs, W. and K. Schugerl: Chem. Ing. Techn., 50, 767 (1978)

6) Kataoka, T.: Kagaku Kögaku, 41, 178 (1977)

7) Kondo, K., K. Kita, I. Koida, J. Irie and F. Nakashio: J. Chem. Eng. Japan, 12, 203 (1979)

8) Li, N. N.: AIChE J., 17, 459 (1971)

9) Mlynek, Y. and W. Resnick: AIChE J., 18, 122 (1972)

10) Schlosser, S. and E. Kossaczky: J. Memb. Sci., 6, 83 (1980)

11) Spraw, F. B.: AIChE J., 13, 995 (1967)

12) Tsukiyama, S. and A. Takamura: Yakugaku Zasshi, 93, 875 (1973)
13) Tsukiyama, S. A. Takahama, Y. Wakamatsu and $I$. Takashima: Yakugaku Zasshi, 93, 191 (1973)

14) Vermeulen, T., G. M. Williams and G. E. Langlois: Chem. Eng. Progr., 51, 85F (1955)

15) Volkel, W., W. Halwachs and K. Schugerl: J. Memb. Sci., 6, 83 (1980)

16) Weinstein, B. and R. E. Treybal, AIChE J., 19, 304 (1973)

17) Yamaguchi, I., S. Yabuta and S. Nagata: Kagaku Kögaku, 27, 576 (1963)

(1980 年 5 月 8 日受理; 化学工学協会第 13 回秋季大会 (名古 屋, 1979 年 10 月) にて発表)

\title{
Mean Drop Diameters of W/O- and (W/O)/W-Dispersions in an Agitated Vessel
}

\author{
Katsuroku Takahashi, Fujio Ohtsubo and Hiroshi Takeuchi \\ Dept. of Chem. Eng., Nagoya Univ., Nagoya 464
}

\begin{abstract}
Diameters of drops in an agitated vessel were measured for water drops dispersed in kerosene (W/O-emulsion) and W/O-emulsion drops dispersed in water ((W/O)/W-dispersion) in the presence of Span-80 as an emulsifying agent.

Drop size distributions for the W/O-emulsion were expressed by a logarithmic normal distribution. Sauter mean diameters for the W/O- and $(\mathrm{W} / \mathrm{O}) / \mathrm{W}$-dispersions depend on the agitation speed, impeller diameter and emulsifying agent concentration. The concentration dependence corresponds to the variation of interfacial tension obtained under dynamic conditions. Water drops dispersed in oil scarcely coalesced when the emulsifying agent was added. As the result, the drop size distribution did not vary with the dispersed-phase holdup fraction, and the effect of Weber number on drop diameter was larger than that reported for system without emulsifying agent.
\end{abstract}

